\title{
A SYSTEMIC APPROACH TO ENTERPRISE CRISIS MANAGEMENT IN THE CURRENT ECONOMIC CONDITIONS
}

\section{Ruslan Mihalachi}

State University of Moldova, Chisinau, Moldova

\section{Natalia Bancila}

Academy of Economic Studies of Moldova, Chisinau, Moldova

OMESTE

JEL Category: C53, H12

\begin{abstract}
Crises are characteristic of any system, including economic entities in the process of its evolution. These usually signal the accumulation of a critical mass - of the restriction factors, the elimination or activation of which is necessary, either to prolong the reproduction process or to move to a new quality. The recent global economic crisis, related to the global pandemic situation, has made crisis management at both macro-economic and micro-economic levels one of the most important management tools to revive the critical situation globally. The crisis at all levels is always accompanied by a chronic organizational and financial instability, determining the need to develop measures that would be coherent in the new conditions of the economic environment accompanied by the political and social. The critical situation in the country's economy is confirmed by the worsening financial situation of domestic enterprises, the increase in losses, and, respectively, the number of enterprises on the verge of bankruptcy. Such a critical situation makes the issue of efficient organization of the management of the activity of enterprises in economic difficulty/crisis extremely topical. From this point of view, choosing the methods of crisis management and transforming them into an effective tool in entrepreneurship is a priority. The decisive role, in this sense, must belong to the diagnosis and financial forecasting of the dangers of crises at the enterprise by considering the factors that caused the crisis or even bankruptcy. The management of financial crises was constrained by the insufficient development of the informational-methodical base in this direction. In this context, not only the local experience but also the global one showed that the use of crisis management is quite difficult from a practical point of view, respectively, it requires an improvement and development in methodological-methodological terms, which requires evaluation of meticulous crises at the enterprise, which allows the diagnosis and prediction of crises with higher accuracy at each stage of its development.
\end{abstract}

Keywords: crisis, risk, economic cycle, crisis management, diagnostic, prediction, systemic approach

The address of the author: Ruslan Mihalachi 表”ruslanmihalachi@yahoo.com

\section{RESEARCH}

During the life cycle, companies go through four phases: emergence, formation, growth, to decline. 
The crisis can occur in each of these phases, respectively, even in the early stages, the company has great chances to end its activity. Such situations can be generated by the internal economic, political, social conditions, external but also internal in which it operates.

This has convinced entrepreneurs, producers, big business owners in all countries during 2020 when the global Pandemic situation was triggered in connection with COVID 19. Therefore, on the one hand, not all companies reach the last stage of the life cycle

For example, from the start-up phase of the enterprise to its formation phase, on average, only $20 \%$ of enterprises reach it. Of the remaining ones, only $40-60 \%$ show flexibility and reach the growth phase, this phase being characterized by a significant development of the economic potential of the enterprise, followed by the phase of decline (crisis).

At this stage, the crisis is conditioned, first, by the aging of the enterprise, which, sooner or later, happens. Reaching this stage of its life cycle, the enterprise has two solutions: or reorganizes (restructures), thus continuing its activity, or is liquidated.

Crisis management must be approached as a system when a complex of measures are taken to combat the unfavorable situation, actions that begin with the diagnosis of the crisis and end with the methods of removing and overcoming it. Crisis management is special management that can forecast and weaken crises, at the same time, to ensure the operation of the company in the survival regime during the crisis and to get it out of this state with minimal losses.

Finally, the main objectives and tasks of crisis management at the enterprise are concentrated in:

1. the anticipation of crises and adequate preparation for them.

2. control and avoidance of crisis factors.

3. managing the dynamics of crisis development (accelerating/slowing it down, weakening/accentuating it).

4. ensuring the survival of the enterprise in the crisis.

5. diminishing the consequences from the crisis.
6. the use of the factors and consequences of the crisis for the transition of the enterprise to a new stage of development.

Overall, we could say that the main objective of crisis management in the enterprise is to ensure its financial stability and a comfortable market position, even in conditions of an unstable economy. It should be noted, however, that at different stages of the crisis, as well as at various changes in the economy, these objectives need to be adjusted and corrected.

To achieve these objectives and tasks, the anticrisis management process at the enterprise is divided into two main directions of action:

I. Preventive actions, avoidance of the crisis at the enterprise.

II. Actions to overcome the crisis (if the company is already in crisis)

The model of anti-crisis management at the enterprise is presented in figure 1.

At the base of the first direction of actions of the anti-crisis management, is the diagnosis and evaluation of the parameters of the crisis at the enterprise, which include the following stages:

- Detailed monitoring of the internal and external environment of the enterprise, in the direction of timely identification of crisis phenomena.

- Identification of deviations from the normal situation, of the signals of crisis, evaluation of these signals.

- Establishing cause-effect links and forecasting the possible directions of development of the crisis, the size of the possible losses.

- Monitoring the state and development of the crisis phenomenon.

- Elaboration of measures regarding the diminution of the external fragility of the company.

- Increasing the internal flexibility of the company.

- The second direction of actions of the anticrisis management is based on the measures to overcome the crisis and stabilize the economic-financial situation of the enterprise. These actions mainly include: 
- Elaboration of plans regarding the avoidance of crises and the preparation of measures regarding the realization of these plans.

- Implementation of these plans in case of a crisis in the enterprise and permanent verification of the implementation of these plans, assessment of results.

- The application after the cause of the whole set of tools and methods regarding the overcoming of the crisis.

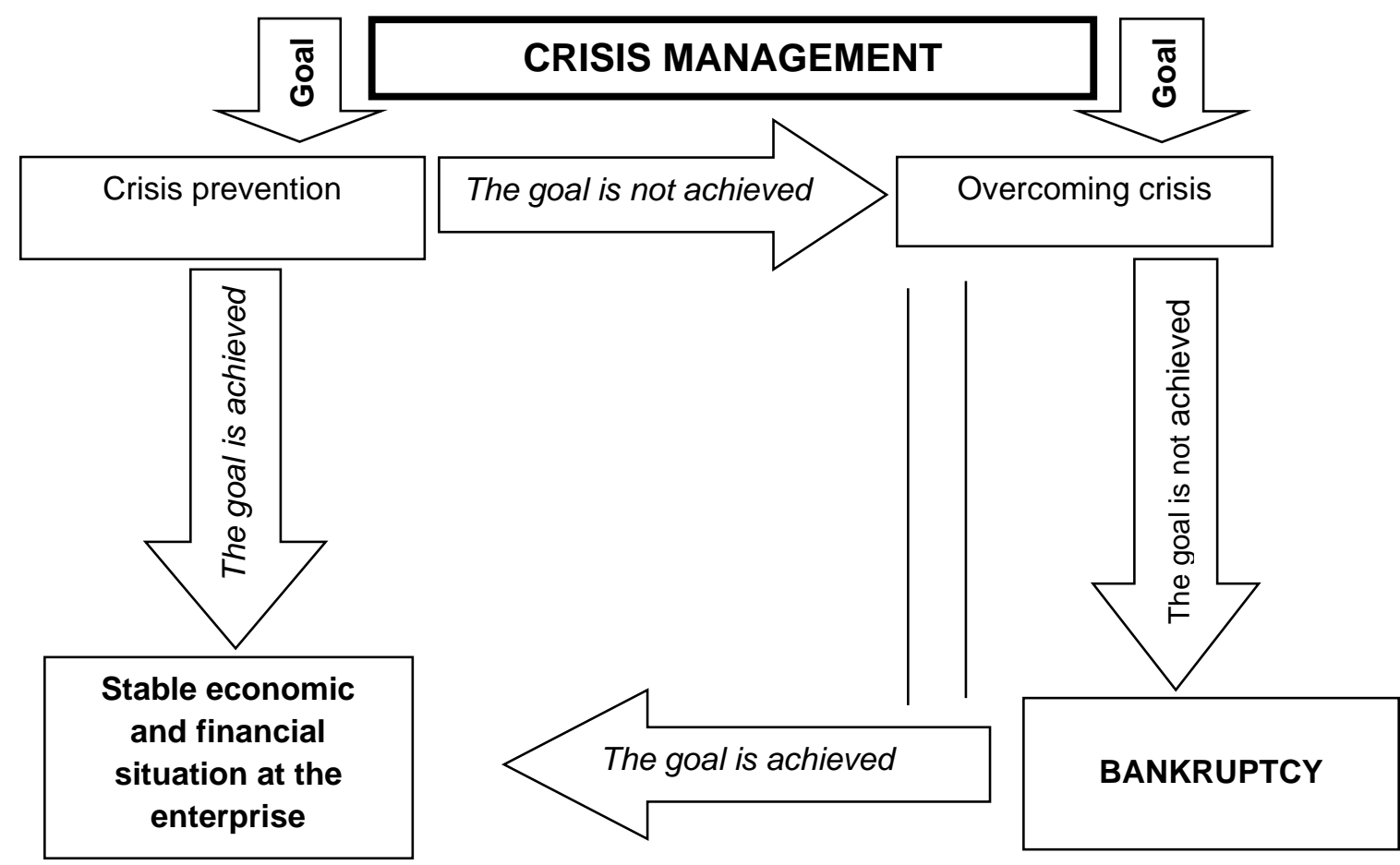

Figure 1 Crisis management model (Tal', 2004)

The implementation of the entire system of actions and measures mentioned above, of the crisis management must be based on a series of specific principles, without which the objectives of the crisis management become difficult to achieve. These principles serve as the basis for the effective organization of anti-crisis management. These are the following:

1. Timely diagnosis of crisis phenomena.

2. Rapid reaction to crisis phenomena.

3. An adequate response to the danger of crisis.

4. The principle of decision-making complexity.

5. The principle of alternative activities.

6. The principle of flexibility and high adaptability.

7. The principle of prioritizing the use of internal sources.

8. The principle of effectiveness.

The effect of crisis management can be appreciated depending on the degree of achievement of its objectives, regarding anticipating-avoiding the crisis, weakening its negative influences, overcoming it.
As for the first principle of the crisis management system, then it can be considered one of the most important. Because avoiding the crisis is possible only through the diagnosis of the possibilities of the crisis. This will allow the company to use the full arsenal of anti-crisis management tools in the fight against the crisis.

The pronounced specificity of the crisis management consists in the combination of strategic and tactical directions, in the operative reaction to the transformations of the external environment, in the elaboration and use of the variants and alternative lines of action. This approach allows the company, at all stages of the crisis development, to identify and optimize the link between risk and profitability.

Namely, this situation and becomes the basic concern of anti-crisis management. Respectively, the anti-crisis policy becomes part of the general financial policy of the company, which focuses on developing the system of methods for early diagnosis (prior) of the danger of bankruptcy and the timely application of financial recovery 
measures, which would ensure the exit from the crisis.

The bankruptcy of enterprises, most of the time, can be encountered, namely, in the conditions of an unstable economy, such as the economy of the Republic of Moldova, accompanied by various imbalances at all levels. These imbalances, constantly, test the management of enterprises, disturbing their normal functioning.

In the conditions in which the enterprise operates successfully on the market, achieving positive economic-financial results, the management of crises must be focused on the operations of prevention and prevention of crisis phenomena. However, with the appearance of the first signs of crisis, the management of crises is activated, and becomes more and more accentuated with the worsening of the internal and external situation of the enterprise.

Here come the tools of crisis management that must be applied, first of all, in the conditions of variations in the external environment (taxes, inflation, interest rate, market factors, etc.), which often generate the crisis and lead the company to bankruptcy.

The efficiency of crisis management is conditioned by the company's ability to react constructively to these variations that threaten its normal operation. This capacity must not depend on the situation in which the bankruptcy procedure itself takes place or only the risk of its occurrence arises. In both the first and the second case, it is necessary to implement anti-crisis decisions, all of which form the core of crisis management. Thus, the efficiency of crisis management in the enterprise depends on the following factors:

1. Professionalism and special training of financial managers, who deal with crisis management.

2. Qualitative functioning of the crisis monitoring system.

3. Early forecasting of crises and elaboration of effective crisis scenarios.

4. Development of the methodology for elaborating financial decisions in crises.

5. The quality of the elaboration of anti-crisis programs.
6. Promoting financial policies appropriate to the external environment of the enterprise.

7. The operability and flexibility of the management in the situation of the permanent change of the external environment.

8. The human factor, solving the problems regarding the communication and collaboration of the staff in a crisis.

At the same time, it is necessary to make and understand the difference between anti-crisis management and traditional management within the enterprise.

The set of problems that anti-crisis management is concerned with shows that it is a special form of management, which includes both general management characteristics and specific characteristics that highlight it compared to traditional management. However, it is necessary to highlight correctly/clearly this specific, as well as the differences between the two types of management (traditional and crisis).

Anti-crisis management is such a type of management that has some features specific only to them. First, in terms of objectives and conditions of achievement, it differs greatly from simple (traditional) management, although even the traditional one, in a broad sense, can be considered anti-crisis. The main differences between them will be presented in the table 1 .

It should be noted that the specificity of crisis management, compared to traditional management, is accentuated as the company approaches the state of crisis and when it approaches bankruptcy or financial crisis. Namely, in this situation, the main objective of crisis management is outlined. Respectively, crisis management can accept any conditions and any losses, for its basic objective to be achieved, namely for the enterprise to survive.

At the same time, the strategic objectives of enterprise development and growth, which are key to traditional management, are completely ignored. Hence the high sensitivity to the time factor, which is the second specificity of anti-crisis management. 
Table 1. The difference between traditional and crisis management (Kovan \& Mokrova, 2009)

\begin{tabular}{|c|c|c|}
\hline Criteria & Traditional Management & Crisis management \\
\hline The objective of management & $\begin{array}{l}\text { Increasing the efficiency of the } \\
\text { company's activity }\end{array}$ & $\begin{array}{l}\text { Minimizing the negative } \\
\text { influences on the activity }\end{array}$ \\
\hline Time and resource constraints & light & acute \\
\hline $\begin{array}{l}\text { The state of the external } \\
\text { environment }\end{array}$ & favorable & unfavorable \\
\hline $\begin{array}{l}\text { The state of the internal } \\
\text { environment }\end{array}$ & stable & Subject to various conflicts \\
\hline The desired result & $\begin{array}{l}\text { Increasing the efficiency of the } \\
\text { company's activity }\end{array}$ & $\begin{array}{l}\text { Avoiding or overcoming crises } \\
\text { with minimal losses (survival) }\end{array}$ \\
\hline
\end{tabular}

This specificity is related to the fact that, following the development of the crisis in the company, it is possible to have irreversible consequences, which can ultimately lead to the liquidation of the company, respectively, the actions of anti-crisis management must be fast, concrete, and safe.

In addition to the time limitation, the enterprise in crisis is tightly limited in other resources: financial, material, human. Under these conditions, there is a need for mobility and a special dynamism, which would allow overcoming the crisis.

However, anti-crisis and traditional management must be applied and carried out in parallel. Their weight, however, can be different, and this, first, depending on the economic-financial state, in which the enterprise is, at the moment, namely: stable state; unstable state (the state that is characteristic, usually, of the pre-crisis or postcrisis situation) and crisis.
For each of these states, crisis management has its specific tasks and, respectively, a certain share that it occupies in the total management system.

In a stable situation, the basic functions of crisis management are limited to measures and actions of prophylaxis, aiming to prevent crisis phenomena for early preparation for possible crises. This phase, called the monitoring phase, allows the timely identification of factors with a negative influence on the activity of the enterprise, respectively, allows the mitigation of the consequences of the crisis. Here the share of crisis management in the total management system is quite small.

In an unstable state of the economic-financial situation of the enterprise, the crisis management enters the crisis regulation phase.

Here are applied the measures to stabilize the situation regarding the stopping of the

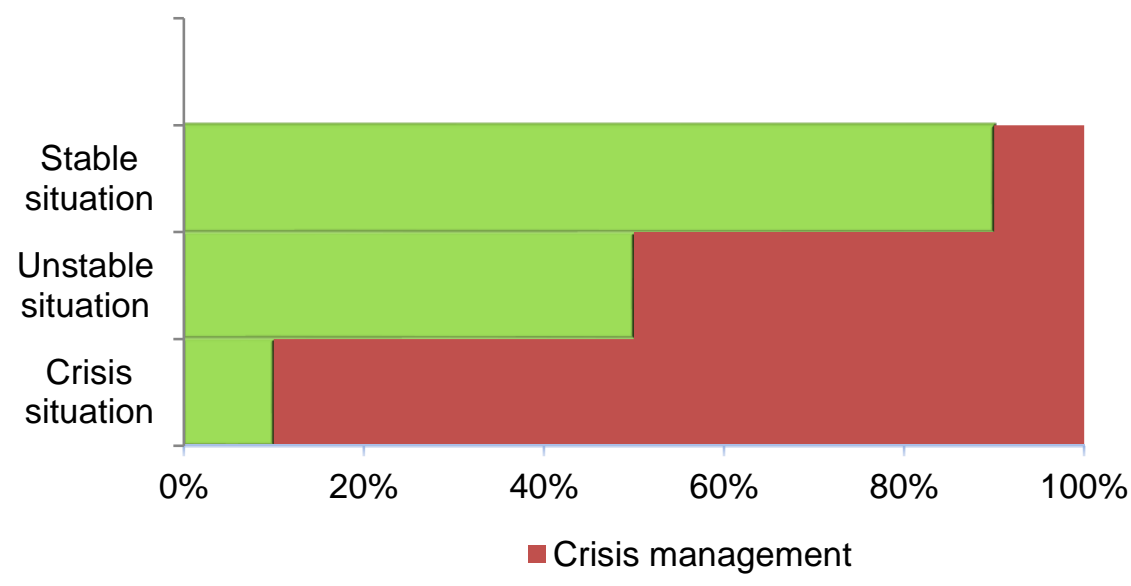

Figure 2 The share of crisis management in total management

Source: Prepared by the authors development and deepening of the crisis phenomena. In this state, the company can be both when it is approaching the crisis, and when the company has just come out of it. At this stage, 
the weights of traditional and crisis management are almost equal.

When the avoidance of the crisis was not possible and the company reaches a state of economic difficulty, the main function of anti-crisis management is to overcome the crisis with minimal losses and return the company to a stable state of operation.

Therefore, we can see that, in any state in which the company is, management must include elements of crisis management and, as the crisis approaches, the role of its functions must immediately increase. At the bottom point (crisis) as we see in figure 2. practically, the entire management is performed in a crisis regime.

On figure 2 we notice that crisis management has a crucial role in the total management system of the enterprise. The practical role of this management can be materialized through the following actions:

- clarifies and solves the problems that appeared in the activity of the enterprise.

- serves as a tool for the survival of the enterprise in difficult times.

- minimizes the risk of bankruptcy.

- coordinates the activity of the whole enterprise.

- $\quad$ highlights priority issues.

- contributes to the rational distribution and use of enterprise resources.

- contributes to the transition of the enterprise to a new stage of development.

Crisis management injects or brings a certain revolutionary dynamism in all elements of the company's management system, forcing it to improve.

In countries with developed economies, crisis management has long become an important tool in the business environment, while in developing countries, such as the Republic of Moldova, other countries in the ex-Soviet space, this tool is just beginning to be used more widely, because in the last year the number of companies on the verge of bankruptcy has increased considerably due to inactivity in the last six months of 2020.

The main problem is that the application of this tool in practice, for enterprises in developing countries, especially in the Republic of Moldova, is quite difficult. This difficulty is related to various problems that companies in these countries face, the main ones being the following:

- distrust in modern formal methods and, in general, in the methodology of crisis management.

- too great variations of the external environment generated by the economicfinancial imbalances and as a result there is distrust in the future.

- the insufficiency of the managers' qualification, their ignorance and inability to lead efficiently the activity of the enterprise.

- rather poor technical, methodological, and informational assurance of enterprise management.

- the need to make additional expenses, related to special research: diagnosis, forecasting, and planning, remuneration of specialists, additional time, etc.

- a rather high degree of uncertainty of the Moldovan market.

- low level of culture of the participants operating on the domestic market.

As mentioned above, crises are different, and their management may be different, respectively. This variety is highlighted in the management system and processes, as well as in the management mechanism. It is important that crisis mechanisms, including the reduction of staff, although this is an extreme measure, to be applied as soon as possible, then the company, in a shorter period and with fewer losses, will overcome the crisis.

The success of crisis management at the enterprise is determined by the degree of preparation of the company's managers towards potential crisis phenomena, the disposition of reserves, the level of prophylactic measures, the degree of efficiency of the applied management methods, etc.

The practice has shown that only an active innovation policy, in combination with the use of investments in the introduction of new technologies and products, allows the successful solution of problems related to avoiding or overcoming crises.

The crisis management in the enterprise must be based on a systemic approach, with interdisciplinary results, which regards the enterprise as a system of elements, realizing the 
full potential of financial management. In this sense, the elements of the enterprise as a system include all the financial, managerial, marketing, and production components. In crisis management, the systemic approach serves as a methodological basis in assessing the crisis of the enterprise, forecasting the development of events, and elaborating decisions to direct these events in the necessary direction.

The basis of the systemic approach involves determining the objectives and tasks of this system in crisis codifications. With its help, the financial managers of the enterprise can understand the essence of the difficulties encountered, which the company encounters, and make the necessary decisions based on the information on the variations of the external and internal environment.

Finally, we can highlight the main elements of the systemic approach to enterprise crisis management:

1. Analysis of the financial situation and evaluation of the company's activity.

2. Elaboration of a real marketing strategy.

3. Applying an innovation-based strategy.

4. Optimal personnel management.

5. Business-crisis planning.

6. Bankruptcy risk assessment.

Applying the systemic approach to enterprise crisis management to practice would allow:

- Considering all factors, both internal and external, with different influences on the enterprise.

- Attracting and concentrating more resources from different levels to manage these factors and solve problems.

- Identify effective ways and means of influencing these factors.

The advantage of the systemic approach is also expressed by the fact that when analyzing a concrete situation in a certain structure of the enterprise, it allows financial managers to consider the effects of its decisions for other structures of the enterprise that are interdependent.

In the author's opinion in economic theory and practice, there is no single recipe, based on which any enterprise could emerge from the crisis, thus solving all its economic and financial problems. Certainly, even the use of the whole arsenal of anti-crisis management tools does not guarantee its avoidance or successful overcoming.

Each enterprise, as well as each crisis, has an individual, specific character, and only through a deep diagnosis of the concrete situation, we can conclude whether the enterprise can successfully avoid/overcome the crisis.

The experience of foreign companies shows that one of the most important factors in the success of the company's activity is its ability to react in time to all changes or variations that take place in the markets, financial markets, and the economy as a whole.

The common aspect of the activity of foreign enterprises consists in the fact that they are directly oriented towards the market, towards the satisfaction of concrete needs, towards the functioning in the conditions of the "productmarket" strategy.

For most domestic enterprises, however, the problem of efficiency is reduced more to survival, as they are often in a state of "chronic" crisis. The most important task for domestic agencies is to maintain payment capacity and eliminate production losses.

In this sense, the priority directions for the activity of the local enterprises can be considered the maintenance of the liquidity and the capital structure within the established limits, as well as the assurance of profitability. At the same time, many of the domestic enterprises are not able to perform even these tasks, thus finding themselves in a situation of the financial crisis.

In many cases, however, the crisis in domestic enterprises could be avoided or at least weakened to such an extent that enterprises can successfully overcome it.

This can be achieved only through the timely diagnosis of crisis phenomena to avoid it or minimize, as much as possible, the negative influences of risk factors that may jeopardize the operation and development of the enterprise. 
Diagnosis is considered one of the most important tools of crisis management because the avoidance or prevention of the crisis is possible only through the diagnosis of its possibilities.

The diagnosis is made through permanent monitoring of the economic and financial situation of the company and external environmental factors, which have a major influence on the activity of the company, which will allow it to obtain the necessary time to avoid the crisis, or at least to weaken it, respectively, to diminish its negative influences, if avoidance is impossible.

The assessment of the symptoms of the crisis must be done before its effects take shape. Thus, this assessment and prognosis of the assessment of crisis symptoms is the main object of crisis diagnosis in the enterprise.

Practice shows that, in the current economic conditions, all aspects of the company's activity can generate the crisis and its bankruptcy, respectively. Therefore, when forming the "crisis field", the most representative elements of the degree of a generation of this danger must be highlighted, first. From this position, the "crisis area" of the enterprise can be presented by the following objects: the volume of sales of the enterprise; net cash flow; the market value of the enterprise; the structure of the company's liabilities; patrimony structure; the structure of enterprise expenses; other elements.

One of the main objectives of crisis diagnosis is to anticipate and forecast it. In the crisis management system, crisis forecasting occupies a major place. Namely, through it, the degree of probability of occurrence of the crisis at the enterprise can be determined.

Considering the specifics of the period of development of the national economy, we can highlight some of the causes that lead to the development of crises in domestic enterprises, the main ones being:

1. Unstable political, economic, and financial situation.

2. High level of inflation.

3. Low transparency of business activity.

4. Poor level of staff training and lack of experience in market economy conditions.
5. The large number of enterprises that have used, outdated means, both physically and morally.

6. The large share of material expenses in the total production cost.

7. Corruption at all economic levels.

In these conditions, we can talk about overcoming the crisis in domestic enterprises, only with the elimination of these problems. However, it is considered that in emerging economies, such as the Republic of Moldova, internal factors are the cause of only $1 / 3$ of corporate bankruptcies, while $2 / 3$ are due to external factors, which prevail over internal ones. For countries with a developed market economy, the situation is opposed.

To diagnose as correctly as possible, at the same time, complete the crisis at the enterprise, the author selected the most important factors, classifying them according to their level of occurrence:

1. Factors from company level.

2. Factors from the market level.

3. Environmental factors.

The formation of this model, in the author's opinion, would be the most correct, if it were based on the principle of the optimal structure of the company's activity. Namely, the optimal structure of one or another parameter of the enterprise can guarantee the stability and accelerated development of its activity, while the deviation from this structure makes it difficult to achieve these objectives, respectively increases the danger of a crisis in the enterprise.

Therefore, a universal crisis forecasting, and anticipation model will be formed, called the "444" model, where the crisis includes the risk elements shown in figure 3.

In Figure 3, also, one can see which elements are included in each of these groups. Each group of elements, from the 3 levels, as we can see, includes 4 factors. Each factor, depending on its condition, is rated with a grade. From note 1 , where the state of the factor is assessed negatively, to note 4 , where the state of the factor is assessed positively:

1. negative.

2. alarming.

3. normal.

4. positive, 
after which based on the arithmetic or weighted average, the entire group of factors at each level is assessed, obtaining a complete assessment of the crisis in the enterprise.

\begin{tabular}{|c|c|c|}
\hline $\begin{array}{c}\text { Factors } \\
\text { at company level }\end{array}$ & $\begin{array}{c}\text { Factors } \\
\text { at the market level }\end{array}$ & $\begin{array}{c}\text { Factors } \\
\text { at the environmental } \\
\text { level }\end{array}$ \\
\hline $\begin{array}{l}\text { 1.Expenditure } \\
\text { structure }\end{array}$ & $\begin{array}{l}\text { 1. Competitive } \\
\text { structure }\end{array}$ & 1. Political \\
\hline 2. Capital stucture & $\begin{array}{l}\text { 2. Customer } \\
\text { structure }\end{array}$ & 2. Social \\
\hline $\begin{array}{l}\text { 3.Organizational } \\
\text { and staff structure }\end{array}$ & $\begin{array}{l}\text { 3. Supplier } \\
\text { structure }\end{array}$ & $\begin{array}{l}\text { 3. Economic and } \\
\text { financial }\end{array}$ \\
\hline $\begin{array}{l}\text { 4.The age structure } \\
\text { of products and } \\
\text { fixed assets }\end{array}$ & $\begin{array}{l}\text { 4. Structure of } \\
\text { substitutable } \\
\text { products }\end{array}$ & 4. Tehnological \\
\hline
\end{tabular}

Figure 3. Crisis factors (model 444) (Mihalachi, 2012)

It should be noted that all the factors presented are, in essence, nothing more than risk factors, therefore, the diagnosis of the crisis in the company must be based specifically on the analysis of the risks to which the company in question is subjected. Analyzing these risks, we will create a complete, broad position of the crisis in the enterprise, and not only of a phase of it. Therefore, we obtain the following form of the model:

\section{Crisis $=$ Own risk + Market risk + Environmental risk .}

\begin{tabular}{|c|c|c|}
\hline Own Risk & Market Risk & $\begin{array}{c}\text { Enviromental } \\
\text { risk }\end{array}$ \\
\hline $\begin{array}{l}\text { 1. Economical } \\
\text { risk }\end{array}$ & $\begin{array}{l}\text { 1.Competetive } \\
\text { risk }\end{array}$ & 1.Political risk \\
\hline $\begin{array}{l}\text { 2. Financial } \\
\text { risk }\end{array}$ & $\begin{array}{l}\text { 2. Comercial } \\
\text { risk }\end{array}$ & 2. Social risk \\
\hline $\begin{array}{c}\text { 3.Managemen } \\
\text { t risk }\end{array}$ & 3. Rupplier risk & $\begin{array}{l}\text { 3.Economical } \\
\text { rsk }\end{array}$ \\
\hline $\begin{array}{c}\text { 4. Tehtechnologic- } \\
\text { prod. risk }\end{array}$ & $\begin{array}{l}\text { 4. Risk of substitutable } \\
\text { products }\end{array}$ & $\begin{array}{l}\text { 4. Tehtechnologic } \\
\text { risk }\end{array}$ \\
\hline
\end{tabular}

Figure 4. Risk structure according to model 444

The application of this model, in crisis management, allows the identification of the crisis from its early phase, which gives the company great chances, at the right time, to correct the erroneous course of its activity which would bring success in avoiding the crisis. or at least weaken it if avoidance is impossible.

In other words, the given model can offer the company's management the possibility to react, in due time, to events that threaten or directly or indirectly affect the economic-financial results of the company, a reaction that could guarantee the economic-financial security of the enterprise.

The importance of this model consists in selecting and systematizing the most important risk factors (in the author's opinion) that generate the crisis in the enterprise. In essence, this model is a system of complex risk analysis of the enterprise and can 
be considered a powerful tool for the diagnosis of the crisis in the enterprise. Therefore, it would be appropriate to use in the management of crises in domestic enterprises.

\section{CONCLUSIONS}

Economic practice shows that one of the most important factors in the success of the company's activity is its ability to react in time to all changes or variations that take place in its internal and external environment.

In most cases, the crisis in the enterprise could be avoided or at least weakened to such an extent that enterprises can successfully overcome it. This can only be achieved through the timely diagnosis of crisis phenomena.

It is worth mentioning that, at present, the problem of bankruptcy forecasting at the enterprise is extremely actual for the enterprises from the Republic of Moldova. At the same time, the issue of choosing methods for crisis prediction, which would allow with high accuracy to predict the state of crisis in the enterprise, is also current.

To be able to forecast and anticipate the crisis from the beginning, a complex approach is needed, much larger in the diagnosis of the crisis, based not only on financial indicators of the company but also on several other indicators that characterize both internal factors. of the enterprise, as well as the external one.
It should be mentioned that, at the current stage of the national economy, the timely identification of negative trends in the development of enterprises, as well as the forecasting of the crisis in their activity, acquires a primary significance. At the same time, there are practically no methods that would make it possible to achieve these things. For this reason, the author aims to develop a complex model for diagnosing and anticipating the crisis in the enterprise considering all aspects and aspects of its activity.

The complex diagnosis of the crisis in the enterprise must begin with the analysis of the risks to which the enterprise in question is subjected. By analyzing these risks, we will create a complete, comprehensive position of the crisis in the enterprise, and not only of a phase of it.

Therefore, to diagnose the crisis in the company as accurately and completely as possible, the author selected the most important risk factors, dividing them according to their level of occurrence. Thus, a universal model for forecasting and anticipating the crisis at the enterprise was developed, called the "444" model.

This model can offer the company's management the possibility to react, in due time, to events that threaten or directly or indirectly affect the economic and financial results of the company, the reaction that could increase the economic and financial security of the company in a perspective. long term.

\section{WORKS CITED}

Kovan, S., \& Mokrova, L. (2009). Teoriya antikrizisnogo upravleniya predpriyatiyem: uchebnoye posobiye. Moskva: KNORUS.

Mihalachi, R. (2012). Management of Financial Crisis Situations in Companies in The Republic of Moldova - doctoral thesis. Moldova State University.

Tal', G. K. (2004). Antikrizisnoye upravleniye: uchebnoye posobiye: V 2 t. Tom II. Ekonomicheskiye osnovy. Moskva: Infra-M.

Received for publication: Revision received:

Accepted for publication:
06.09 .2020

22.09.2020

30.12 .2020 


\section{How to cite this article?}

Style - APA Sixth Edition:

Mihalachi, R., \& Bancila, N. (2021, January 15). A systemic approach to enterprise crisis management in the current economic conditions. (Z. Cekerevac, Ed.) MEST Journal, 9(1), 135-145. doi:10.12709/mest.09.09.01.16

Style - Chicago Sixteenth Edition:

Mihalachi, Ruslan, and Natalia Bancila. 2021. "A systemic approach to enterprise crisis management in the current economic conditions." Edited by Zoran Cekerevac. MEST Journal (MESTE) 9 (1): 135-145. doi:10.12709/mest.09.09.01.16.

Style - GOST Name Sort:

Mihalachi Ruslan and Bancila Natalia A systemic approach to enterprise crisis management in the current economic conditions [Journal] // MEST Journal / ed. Cekerevac Zoran. - Belgrade - Toronto : MESTE, January 15, 2021. - 1 : Vol. 9. - pp. 135-145.

Style - Harvard Anglia:

Mihalachi, R. \& Bancila, N., 2021. A systemic approach to enterprise crisis management in the current economic conditions. MEST Journal, 15 January, 9(1), pp. 135-145.

Style - ISO 690 Numerical Reference:

A systemic approach to enterprise crisis management in the current economic conditions. Mihalachi, Ruslan and Bancila, Natalia. [ed.] Zoran Cekerevac. 1, Belgrade - Toronto : MESTE, January 15, 2021, MEST Journal, Vol. 9, pp. 135-145 